\title{
Sistem Pendukung Keputusan Dalam Memilih Bahan Furniture Terbaik Menggunakan Metode Simple Addative Weighting (SAW)
}

\author{
Bella Klaranita ${ }^{1}$, Gingin Septilaila ${ }^{2}$, Ira Saniatul Afifah ${ }^{3}$, Mulia Rahmayu ${ }^{4}$
}

\begin{abstract}
Sistem pendukung keputusan ini dibuat untuk mempermudah costumer dalam memilih bahan furniture yang bagus dan sesuai dengan kebutuhan yang akan digunakan, serta bisa menjadi tolak ukur dana atau budget berapa yang akan dikeluarkan. Dengan adanya sistem pendukung keputusan ini diharapkan nantinya hasil ini dapat berguna baik bagi perusahaan maupun costumer. Secara garis besar sistem pendukung keputusan ini merupakan proses membandingkan antara jenis-jenis bahan furniture yang satu dengan yang lain, semakin lama ketahanan bahan furniture maka akan semakin bagus. Kriteria furniture yang bagus dapat dilihat dari ketahanan, sifat mekanik kayu dan harga. Untuk merancang Sistem Pendukung Keputusan dalam memilih bahan furniture terbaik ini menggunakan metode Simple Additive Weighting $(S A W)$, karena metode ini sangat cocok digunakan untuk perhitungan yang akurat dan sangat membantu dalam perhitungan setiap data yang diperoleh dalam skripsi ini.
\end{abstract}

Kata Kunci: Sistem Pendukung Keputusan, Metode Simple Additive Weigthing (SAW), Memilih Bahan Furnitre Terbaik.

\begin{abstract}
This decision support system is made to make it easier for customers to choose furniture that is good and in accordance with the needs to be used, and can be used as a benchmark for how much funds or budget to spend With this decision support system, it is hoped that later these results can be useful for both the company and the customer. Broadly speaking, this decision support system is a process of comparing types of furniture materials with one another, the longer the durability of the furniture materials, the better. The criteria for good furniture can be seen from the durability, mechanical properties of wood and price. To design a Decision Support System in choosing the best furniture material, the Simple Additive Weighting (SAW)method is used, because this method is very suitable for accurate calculations and is very helpful in calculating any data obtained in this thesis.
\end{abstract}

Keywords: Decision Support System, Simple Additive Weighting Method (SAW), Choosing the Best Furniture Materials.

\section{PENDAHULUAN}

Dalam pembuatan setiap furniture menggunakan material yang berbeda-beda yang sesuai dengan kebutuhan fungsional dan harga pasar. Bahan dasar yang paling sering digunakan dalam pembuatan furniture yaitu menggunakan bahan kayu. Kayu menjadi bahan utama dalam setiap pembuatan furniture apapun. namun, dari berbagai jenisnya kayu memiliki kelebihan dan kekurangnnya masing-masing. Hal ini menjadikan sebuah pertimbangan dalam perusahaan saat membuat furniture.

Furnil Furniture merupakan sebuah perusahaan start up dibidang penjualan furniture online. Ada berbagai jenis furniture yang di jual dan tentunya setiap furniture memiliki bahan yang berbeda. Ada beberapa bahan yang digunakan, dalam pembuatan furniture, tetapi bahan yang sering digunakan adalah $M D F$, particle board, plywood, dll. Namun, masih banyaknya customer yang tidak mengetahui kekurangan dan kelebihan berdasarkan jenis dari bahan tersebut. Berdasarkan permasalahan yang ada maka dibangun sistem pendukung keputusan untuk membantu customer dalam memilih bahan furniture terbaik. Sistem pendukung keputusan menurut Gorry Dan Scout Morton adalah sistem berbasis komputer interaktif, yang membantu para pengambil keputusan untuk menggunakan data dan berbagai model untuk memecahkan masalah-masalah tidak terstruktur[1].

Dalam sistem pengambilan keputusan sangat penting dalam pemilihan bahan dan kualitas produk agar tak terjadi kesalahan dalam pembelian furniture sesuai dengan fungsi kebutuhan. Proses pengambilan keputusan harus metode yang digunakan yaitu Metode Simple Additive Weighting (SAW) yang akan berkerja untuk menentukan pemilihan bahan dan kualitas furniture. Metode Simple Additive Weighting (SAW) sering juga dikenal istilah metode penjumlahan terbobot. Konsep dasar metode Simple Additive Weighting (SAW) adalah mencari penjumlahan terbobot dari rating kinerja pada setiap alternatif pada semua atribut[2].

\section{METODE PENELITIAN}

Dalam menyusun skripsi ada beberapa tahapan penelitian yang dilakukan oleh penulis untuk membantu pelaksanaan menjadi terarah dengan baik dan sistematis.

\section{Data Kuantitatif}

Data yang digunakan dalam penelitian ini adalah data primer yang didapat dari Furnil Furniture sesuai wawancara dari karyawan-karyawan yang dijadikan objek penelitian dan
Universitas Nusa Mandiri, Jl. Kamal Raya No. 18, RT.1/RW.6, Ring Road Barat, Cengkareng Barat, Cengkareng, RT.6/RW.3, Cengkareng Barat, Kecamatan Cengkareng, Kota bellaklaranita@gmail.com irasaniatul05@gmail.com,mulia.mlh@nusamandiri.ac.id hasil dari observasi menganalisis suatu masalah.

ginginsepti20@gmail.com, 


\section{Kuisioner}

Penulis mengambil data kuisioner dari customer lalu akan dicocokan dengan data Simple Additive Weighting (SAW), karena data Simple Additive Weighting (SAW) diperoleh dari perusahaan sedangkan data kuisioner diperoleh dari costumer. Maka keduanya akan dicocokan sesuai dengan bahan furniture yang akan digunakan sesuai kebutuhan costumer.

Terdapat beberapa informasi yang dibutuhkan penulis dari tahapan penelitian. Berikut metodologi yang dilakukan oleh penulis.

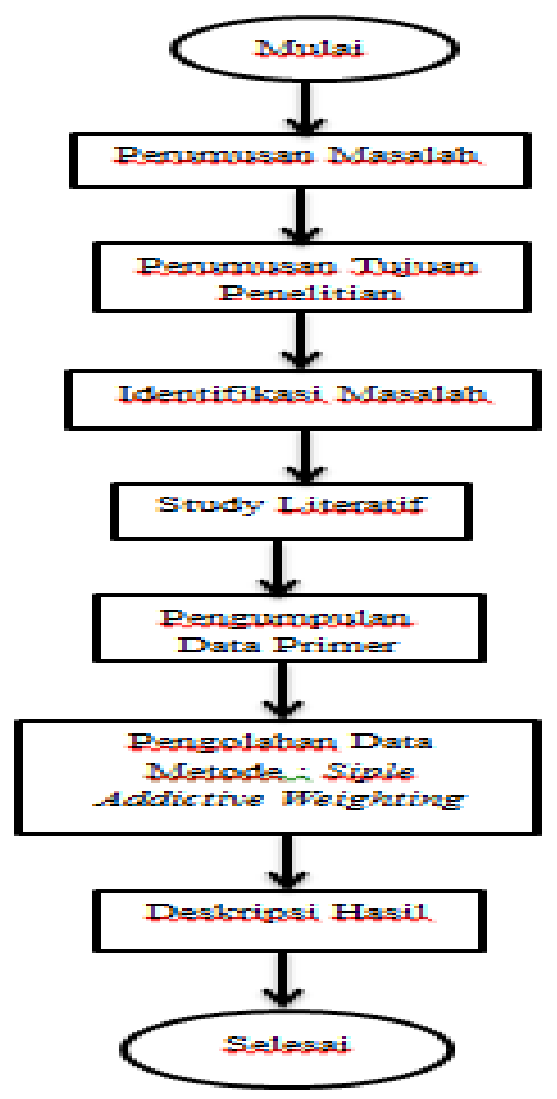

Gambar III.1 Tahapan Penelitian

Sumber: Data Penelitian 2021

\section{Perumusan Masalah}

Pada tahapan ini penulis mencari dan mempelajari permasalahan yang ada pada Furnil Furniture dan mencari referensi serta teori yang relavan untuk mendapat solusi yang tepat dari permasalahan yang ada.

\section{Perumusan Tujuan Penelitian}

Pada tahap ini penulis menentukan pemecahan masalah yang terjadi pada Furnil Furniture sehingga memudahkan bagian Pemasaran dalam melakukan kegiatan pekerjaan secara cepat dan akurat. Penelitian ini juga berfungsi untuk membuat sistem pendukung keputusan yang berguna untuk customer dalam memilih bahan furniture yang sesuai dengan kebutuhan.

\section{Identifikasi Masalah}

Penulis melakukan identifikasi yang berkaitan dengan masalah yang ada di Furnil Furniture, mulai dari customer kesulitan dalam memilih jenis bahan hingga bahan bagus yang bisa diterapkan menggunakan metode Simple Additive Weigthing (SAW).

\section{Studi Literatur}

Literature dipakai sebagai kajian teori dalam penelitian yang terjadi pada Furnil Furniture terdapat beberapa kriteria dalam pemilihin jenis bahan furniture, yaitu bagaimana memilih macam-macam bahan yang berbeda dari satu bahan ke bahan yang lain, dan pemilihan bahan yang tepat sesuai dengan kebutuhan.

\section{Pengumpulan Data Primer}

Data primer yang diperlukan untuk penelitian ini adalah berupa wawancara. Bentuk wawancara ini seputar mengenai jenis bahan yang digunakan, kuliatas bahan, dan harga.

6. Deskripsi Hasil

Berdasarkan hasil penelitian dan teori yang ada sehingga dapat ditarik kesimpulan dan tercipta solusi yang sesuai dengan maksud dan tujuan.

\section{HASIL DAN PEMBAHASAN}

Dalam menyelesaikan permasalahan menggunakan metode Simple Additive Weighting (SAW) maka diperlukan kriteria dan bobot, dalam hal ini costumer menentukan kriteria sebagai acuan untuk melakukan perhitungan sehingga akan mendapatkan alternative terbaik. Dibawah ini contoh kasus pemilihan jenis bahan furniture terbaik:

Contoh kasus pemilihan jenis bahan furniture:

Seorang costumer ingin membeli sebuah furniture untuk mengisi interior rumahnya. Ada banyak jenis bahan furniture dan setiap jenisnya memiliki fungsi dan kualitasnya masing-masing, tetapi costumer mengalami kesulitan dalam memilih bahan furniture. Hal inilah yang menyebabkan costumer harus pandai-pandai memilih bahan furniture mana yang akan di beli yang sesuai dengan kriteria-kriteria yang diinginkan.

Berdasarkan contoh kasus di samping maka di dapat 4 kriteria untuk memilih jenis bahan furniture terbaik menggunakan metode Simple Additive Weighting (SAW), berikut kriteria yang akan dijadikan acuan dalam pengambilan keputusan:

Tabel IV.1

Kriteria

\begin{tabular}{|c|c|}
\hline \multicolumn{2}{|c|}{ Kriteria } \\
\hline Kriteria & Nama Kriteria \\
\hline C1 & Harga \\
\hline
\end{tabular}




\begin{tabular}{|c|c|}
\hline C2 & Kualitas \\
\hline C3 & Ketahanan \\
\hline C4 & Sifat Mekanik Kayu \\
\hline
\end{tabular}

Sumber: Hasil Penelitian 2021

Dalam metode Simple Additive Weighting (SAW) terdapat kriteria-kriteria untuk menentukan penilaian. Adapun bobot setiap kriteria dari kriteria tersebut akan ditentukan bobot-bobotnya. Dalam penentuan bobot ada 3 macam pendekatan, Pendekatan-pendekatan untuk menentukan nilai bobot pada kriteria adalah sebagai berikut[8]:

1. Pendekatan subyektif. Nilai bobot ditentukan berdasarkan subyektifitas dari para pengambil keputusan, sehingga beberapa faktor dalam proses perangkingan alternatif bisa.

2. Pendekatan obyektif. Nilai bobot dihitung secara matematis sehingga mengabaikan subyektifitas dari pengambil keputusan.

Pendekatan integrasi antara subyektif dan obyektif Bobot kriteria dari masing-masing atribut peneliti dapatkan dari sumber manajemen Furnil Furniture yang memberikan penilaian dalam pemilihan bahan furniture. Berikut bobot yang diberikan perusahaan untuk setiap kriteria sebagai penilaian untuk pemilihan:

Table IV.2

Bobot Kriteria

\begin{tabular}{|c|c|c|}
\hline \multirow{2}{*}{ Kriteria } & Nama Kriteria & Bobot \\
\cline { 2 - 3 } & Harga & 0.30 \\
\hline C2 & Kualitas & 0.25 \\
\hline C3 & Ketahanan & 0.25 \\
\hline C4 & Sifat Mekanik Kayu & 0.20 \\
\hline
\end{tabular}

Sumber: Furnil Furniture 2021

Selanjutnya menentukan nilai bobot dari setiap variable kriteria, dimana dari setiap variable akan diberi sebuah nilai bobot dalam bentuk angka. Pada studi kasus ini akan mengambil range $1-5$, berikut nilai bobot untuk setiap variable kriteria:

Tabel IV.3

Bobot Harga (C1)

\begin{tabular}{|c|c|c|}
\hline No & Harga & Nilai \\
\hline 1 & $\operatorname{Rp~} 50.000-\operatorname{Rp~} 200.000$ & 1 \\
\hline 2 & $\operatorname{Rp~} 250.000-\operatorname{Rp} 450.000$ & 2 \\
\hline 3 & $\operatorname{Rp~} 500.000-\operatorname{Rp} 650.000$ & 3 \\
\hline 4 & $\operatorname{Rp} 700.000-\operatorname{Rp~} 1.500 .000$ & 4 \\
\hline
\end{tabular}

Sumber: Hasil Penelitian 2021
Berdasarkan tabel IV.3. dapat di lihat hasil bobot harga, maka kriteria harga masuk ke dalam kategori Cost.

Table IV.4

Bobot Kualitas (C2)

\begin{tabular}{|c|c|c|}
\hline No & Kualitas & Nilai Bobot \\
\hline 1 & Kurang Bagus & 1 \\
\hline 2 & Bagus & 3 \\
\hline 3 & Sangat Bagus & 5 \\
\hline
\end{tabular}

Sumber: Hasil Penelitian 2021

Berdasarkan tabel IV.4. dapat di lihat hasil bobot kualitas, maka kriteria kualitas masuk ke dalam kategori Benefit.

Tabel IV.5

Bobot Ketahanan (C3)

\begin{tabular}{|c|c|c|}
\hline No & Ketahanan & Nilai Bobot \\
\hline 1 & 1-2 Tahun & 1 \\
\hline 2 & 3-5 Tahun & 2 \\
\hline 3 & 6-8 Tahun & 3 \\
\hline 4 & $9-10$ Tahun & 4 \\
\hline
\end{tabular}

Sumber: Hasil Penelitian 2021

Berdasarkan tabel IV.4. dapat di lihat hasil bobot kualitas, maka kriteria kualitas masuk ke dalam kategori Benefit.

Tabel IV.6 Bobot Sifat Mekanik Kayu (C4)

\begin{tabular}{|c|c|c|}
\hline No & Sifat Mekanik Kayu & Nilai \\
\hline 1 & Mudah Rapuh & 2 \\
\hline 2 & Cukup Keras & 3 \\
\hline 3 & Keras & 4 \\
\hline 4 & Sangat Keras & 5 \\
\hline
\end{tabular}

Sumber: Hasil Penelitian 2021

Berdasarkan tabel IV.4. dapat di lihat hasil bobot kualitas, maka kriteria kualitas masuk ke dalam kategori Benefit.

Table IV.7.

Rating Kecocokan Setiap Alternatif Pada setiap Kriteria

\begin{tabular}{|c|c|c|c|c|}
\hline \multirow{2}{*}{ Alternative } & C1 & C2 & C3 & C4 \\
\hline Plywood & $\mathbf{4}$ & $\mathbf{3}$ & $\mathbf{4}$ & $\mathbf{4}$ \\
\hline Blockboard & $\mathbf{2}$ & $\mathbf{3}$ & $\mathbf{2}$ & $\mathbf{3}$ \\
\hline Mdf & $\mathbf{2}$ & $\mathbf{3}$ & $\mathbf{3}$ & $\mathbf{4}$ \\
\hline Particle Board & $\mathbf{1}$ & $\mathbf{1}$ & $\mathbf{1}$ & $\mathbf{2}$ \\
\hline
\end{tabular}

Sumber: Hasil Penelitian 2021

Berikut matrik keputusan $\mathrm{X}$ yang dibentuk dari tabel rating kecocokan dari setiap alternatif pada setiap kriteria. 


$$
X=\left(\begin{array}{cccc}
4 & 3 & 4 & 4 \\
2 & 3 & 2 & 3 \\
2 & 3 & 3 & 4 \\
1 & 1 & 1 & 2
\end{array}\right)
$$

Menghitung nilai rating kinerja ternormalisasi (rij) dari alternatif $(\mathrm{Ai})$ pada kriteria $(\mathrm{Cj})$ menggunakan rumus:

$r_{i j}=\left\{\frac{X i j}{{ }^{\operatorname{Max} \mathrm{Xij}}}\right\}$

Jika $\mathrm{j}$ adalah atribut keuntungan (benefit)

$r_{i j}=\left\{\frac{{ }_{i} X i j}{X i j}\right\}$

Jika $\mathrm{j}$ adalah atribut biaya (cost)

1. Normalisasi untuk harga

$\mathrm{r}_{11}=\frac{\operatorname{Min}\{4 ; 2 ; 2 ; 1\}}{4}=\frac{1}{4}=0.25$

$\mathrm{r}_{21}=\frac{\operatorname{Min}\{4 ; 2 ; 2 ; 1\}}{2}=\frac{1}{2}=0.50$

$\mathrm{r}_{31}=\frac{\operatorname{Min}\{4 ; 2 ; 2 ; 1\}}{2}=\frac{1}{2}=0.50$

$\mathrm{r}_{41}=\frac{\operatorname{Min}\{4 ; 2 ; 2 ; 1\}}{1}=\frac{1}{1}=1.00$

2. Normalisasi untuk kualitas

$\mathrm{r}_{13}=\frac{3}{\operatorname{Max}\{3 ; 3 ; 3 ; 1\}}=\frac{3}{3}=1.00$

$\mathrm{r}_{23}=\frac{3}{\operatorname{Max}\{3 ; 3 ; 3 ; 1\}}=\frac{3}{3}=1.00$

$\mathrm{r}_{33}=\frac{3}{\operatorname{Max}\{3 ; 3 ; 3 ; 1\}}=\frac{3}{3}=1.00$

$\mathrm{r}_{43}=\frac{1}{\operatorname{Max}\{3 ; 3 ; 3 ; 1\}}=\frac{1}{3}=0.33$

3. Normalisasi untuk ketahanan

$\mathrm{r}_{14}=\frac{4}{\operatorname{Max}\{4 ; 2 ; 3 ; 1\}}=\frac{4}{4}=1.00$

$\mathrm{r}_{24}=\frac{2}{\operatorname{Max}\{4 ; 2 ; 3 ; 1\}}=\frac{2}{4}=0.50$

$\mathrm{r}_{34}=\frac{3}{\operatorname{Max}\{4 ; 2 ; 3 ; 1\}}=\frac{3}{4}=0.75$

$\mathrm{r}_{44}=\frac{1}{\operatorname{Max}\{4 ; 2 ; 3 ; 1\}}=\frac{1}{4}=0.25$

4. Normalisasi untuk sifat mekanik bahan

$\mathrm{r}_{12}=\frac{4}{\operatorname{Max}\{4 ; 3 ; 4 ; 2\}}=\frac{4}{4}=1.00$

$\mathrm{r}_{22}=\frac{3}{\operatorname{Max}\{4 ; 3 ; 4 ; 2\}}=\frac{3}{4}=0.75$

$\mathrm{r}_{32}=\frac{4}{\operatorname{Max}\{4 ; 3 ; 4 ; 2\}}=\frac{4}{4}=1.00$

$\mathrm{r}_{42}=\frac{2}{\operatorname{Max}\{4 ; 3 ; 4 ; 2\}}=\frac{2}{4}=0.50$

Hasil Nilai Rating Kinerja Ternormalisasi membentuk sebuah matriks ternormalisasi R:

$$
R=\left(\begin{array}{cccc}
0.25 & 1.00 & 1.00 & 1.00 \\
0.50 & 1.00 & 0.50 & 0.75 \\
0.50 & 1.00 & 0.75 & 1.00 \\
1.00 & 0.33 & 0.25 & 0.50
\end{array}\right)
$$

Hasil akhir nilai preferensi (Vi) diperoleh dari penjumlahan dari perkalian elemen baris matrik ternormalisasi (R) menggunakan bobot preferensi (W) yang sesuai dengan elemen kolom matrik (W).
Keterangan:

$$
V_{i}=\sum_{j=1}^{n} w_{j} r_{i j}
$$

$\mathrm{V}_{\mathrm{i}}=$ rangking untuk setiap alternatif

$W_{j}=$ nilai bobot dari setiap kriteria

$r_{i j}=$ nilai rating kinerja ternormalisasi

Berikut perhitungannya:

$$
\begin{aligned}
& \mathrm{V}_{1}=(0.30 \times 0.25)+(0.25 \times 1.00)+(0.25 \times 1.00)+(0.20 \times \\
& \text { 1.00) } \\
& =0.075+0.25+0.25+0.20 \\
& =0.775 \\
& \mathrm{~V}_{2}=(0.30 \times 0.50)+(0.25 \times 1.00)+(0.25 \times 0.50)+(0.20 \times \\
& 0.75) \\
& =0.15+0.25+0.125+0.15 \\
& =0.675 \\
& \mathrm{~V}_{3}=(0.30 \times 0.50)+(0.25 \times 1.00)+(0.25 \times 0.75)+(0.20 \times \\
& \text { 1.00) } \\
& =0.15+0.25+0.1875+0.20 \\
& =0.7875 \\
& \mathrm{~V}_{4}=(0.30 \times 1.00)+(0.25 \times 0.33)+(0.25 \times 0.25)+(0.20 \times \\
& 0.50) \\
& =0.30+0.0825+0.0625+0.10 \\
& =0.545
\end{aligned}
$$

Dari hasil perangkingan di atas penulis dapat menyimpulkan hasil dengan perangkingan nilai $\mathrm{V}_{\mathrm{i}}$ dari nilai terbesar hingga nilai terkecil, nilai alternatif tertinggi adalah $\mathrm{V}_{3}$ bahan kayu MDF.

Berikut tabel hasil perhitungan menggunakan Simple Additive Weighting (SAW):

Tabel IV.8

Potensi Hasil

\begin{tabular}{|c|c|c|c|}
\hline No & Alternatif & Hasil Akhir & Rank \\
\hline 1 & Plywood & 0.775 & 2 \\
\hline 2 & Blockboard & 0.675 & 3 \\
\hline 3 & MDF & 0.7875 & 1 \\
\hline 4 & Particle Board & 0.545 & 4 \\
\hline
\end{tabular}

Sumber: Hasil Penelitian 2021

Dari tabel di atas dapat di lihat bahan furniture terbaik yang cocok untuk mengisi interior rumah adalah bahan MDF dengan harga yang terjangkau, kualitas bahan bagus, ketahanan bahan 6 tahun dan sifat mekanik bahan keras. Dengan adanya perhitungan metode Simple Additive Weighting (SAW) penulis dapat memberikan sebuah hasil keputusan yang lebih tepat dan akurat, sehingga dapat mengetahui bahan furniture terbaik untuk digunakan sebagai material utama dalam pembuatan furniture serta dapat mengetahui kelebihan dan kekurangan dari masing-masing alternatif. 


\section{KESIMPULAN}

Setelah melalui beberapa tahapan penelitian, penulis dapat mengambil kesimpulan mengenai memilih bahan furniture terbaik untuk keperluan interior rumah yang akan digunakan dengan mengambil empat besar alternatif yang terdapat pada perusahaan Furnil Furniture. Kesimpulan yang didapat adalah sebagai berikut:

1. Hasil penelitian dalam menghitung dengan menggunakan metode Simple Additive Weighting (SAW) menunjukkan bahwa alternatif yang paling unggul adalah bahan kayu MDF dengan hasil akhir 0.7875 .

2. Dalam pemecahan permasalahan, penulis dapat menentukan bahan furniture terbaik dengan menggunakan metode Simple Additive Weighting (SAW).

3. Dengan adanya penelitian ini terdapat kelebihannya yaitu, penulis dapat mengetahui jenis-jenis bahan furniture yang digunakan.

4. Selain kelebihan, Adapun kekurangan dalam melakukan penelitian mengenai memilih bahan furniture terbaik. Sulitnya menentukan harga naik turunnya harga dari rekan pabrik yang beredar di pasaran.

\section{REFERENSI}

[1] P. Soepomo, "Sistem Pendukung Keputusan Penentuan Kualitas Kayu Untuk Kerajinan Meubel,” J. Sarj. Tek. Inform., vol. 1, no. 1, pp. 327 337, 2013, doi: 10.12928/jstie.v1i1.2548.

[2] W. Setiyaningsih, Konsep Sistem Pendukung Keputusan. 2015.

[3] Rusito, "Kualitas Kayu Olahan Menggunakan Metode Simple Additive Weighting ( Saw )," J. Infokam, vol. 2, no. 2, pp. 1-14, 2017, [Online]. Available: http://amikjtc.com/jurnal/index.php/jurnal/article/view/125

[4] M. Saw, B. Web, R. Fauzan, Y. Indrasary, and N. Muthia, "Sistem Pendukung Keputusan Penerimaan Beasiswa Bidik Misi di POLIBAN Dengan," vol. 2, no. 2, pp. 79-83, 2017, doi: 10.15575/join.v2i2.101.

[5] B. A. Tf and D. Susilawati, "Penggunaan Material Furnitur Sebagai Pendukung Tema Pada Desain Interior Nanny' S Pavillon Di Bandung," J. Rekajiva J. Online Inst. Teknol. Nas., vol. 01, no. 02, pp 1-14, 2013.

[6] S. S. Abdullah, "Media Jurnal Informatika," vol. 12, no. 1, 2020.

[7] M. Kom, R. Indriati, and M. Kom, "PEMILIHAN KUALITAS KAYU FURNITURE MENGGUNAKAN METODE SIMPLE ADDITIVE WEIGHTING ( SAW ) Oleh: RACHMAD ALKA WISNUWARDHANA Dibimbing oleh: SURATPERNYATAAN ARTIKEL SKRIPSI TAHUN 2018,” pp. 0-9, 2018.

[8] M. Kom, R. Indriati, and M. Kom, "PEMILIHAN KUALITAS KAYU FURNITURE MENGGUNAKAN METODE SIMPLE ADDITIVE WEIGHTING ( SAW ) Oleh: RACHMAD ALKA WISNUWARDHANA Dibimbing oleh: SURATPERNYATAAN ARTIKEL SKRIPSI TAHUN 2018,” pp. 0-9, 2018.

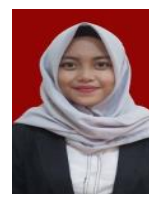

Bella Klaranita. Jakarta 08 Agustus 1999. STMIK NUSA MANDIRI. Magang di FURNIL FURNITURE.

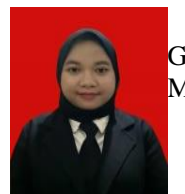

Gingin Septi Laila. Jakarta, 20 September 1999. STMIK NUSA MANDIRI. Praktek Kerja Lapangan di PT PLN (Persero)

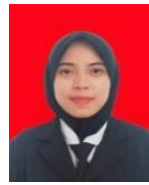

Ira Saniatul Afifah. Ciamis 05 November 1998. STMIK NUSA MANDIRI. Praktek Kerja Lapangan di PT PLN (Persero) 